\title{
Oxidation Behavior of AlTiN/TiN Nanolayer Hard Coating at High Temperatures
}

\begin{abstract}
H. ÇALIŞKAN ${ }^{a *}$ AND A.C. KARAOĞLANLi ${ }^{b}$
${ }^{a}$ Bartın University, Department of Mechanical Engineering, 74100 Bartın, Turkey

${ }^{b}$ Bartın University, Department of Metallurgical and Materials Engineering, 74100 Bartın, Turkey

Hard machining and high speed cutting are challenging machining processes demanded for high productivity for several decades. Hard coatings are mostly used for protection of the tool materials from severe tribological conditions in which excessive cutting temperatures and forces take place during these processes. Oxidation resistance is an important property of the hard coatings in hard machining operations due to high temperatures up to $1000{ }^{\circ} \mathrm{C}$ at the cutting edge. Improvement of oxidation resistance provides longer tool life at dry cutting conditions. TiAlN-based coatings are known to have high oxidation resistance. In this paper, nanolayer AlTiN/ TiN coating was deposited on cemented carbide substrates by industrial magnetron sputtering system. The need to understand the effect of nanolayered structure on the oxidation behavior of protective coatings in machining industry in terms of high temperature oxidation tests is the motivation of this investigation. The deposited coating was annealed at $1000{ }^{\circ} \mathrm{C}$ with different durations. Before and after the oxidation tests, the composition, structure and phases of the coating were determined by scanning electron microscopy in combination with energy-dispersive $\mathrm{X}$-ray spectroscopy and X-ray diffraction, respectively. It was found that nanolayered structure improves oxidation resistance, and thereby, it provides longer tool life.
\end{abstract}

DOI: $10.12693 /$ APhysPolA.125.456

PACS: 68.60.Dv, 64.75.St, 52.70.La, 68.37.Hk, 68.55.Nq

\section{Introduction}

Superior properties such as high hardness and oxidation resistance are highly demanded from hard coatings deposited on cutting tools used in developing applications such as hard machining. The coatings are subjected to high temperatures reaching to $800{ }^{\circ} \mathrm{C}$ during cutting, and this necessitates the coating to be resistant to oxidation. TiAlN coating is well known to be resistant to oxidation and wear due to the growing $\mathrm{Al}_{2} \mathrm{O}_{3}$ layer on the coating at high application temperatures under dry conditions, and, therefore, it is widely investigated and used with cutting tools [1-4]. Using AlTiN coating with high Al concentration, superior oxidation resistance can be obtained. Nanolayer (nl) AlTiN/TiN hard coating which is obtained by sequential deposition of AlTiN and TiN layers has been studied by researchers and found to have high adhesion to substrate and provide longer tool life [5-7]. Therefore, nl-AlTiN/TiN hard coatings are good candidates for machining of hardened steels ( $>55 \mathrm{HRc}$ ), titanium and nickel based alloys. On the other hand, the information on the effect of nanolayered design on the oxidation resistance of coatings is limited. Therefore, in this study, nl-AlTiN/TiN coatings was deposited on carbide cutting tools, and the effect of nanolayered structure on the oxidation resistance of AlTiN and TiN coating was investigated.

*corresponding author; e-mail: hcaliskan@bartin.edu.tr, halilcaliskan06@yahoo.com

\section{Experimental}

Carbide milling inserts, produced by SECO Tools, were used as substrate for deposition of the nl-AlTiN/ TiN coating. Industrial magnetron sputtering system CC800/9 sinOx ML (CemeCon) was used for deposition of the nl-AlTiN/TiN coatings onto the inserts. The deposition system has four unbalanced magnetron sources placed on the corners of rectangle. Three segmental TiAl targets and one Ti target were used for deposition of the nl-AlTiN/TiN coating. The samples were moved in a threefold rotation to obtain structures in nanoscale and also to ensure a constant film thickness distribution at the substrates. Prior to deposition the samples were ultrasonically cleaned and ion-etched in the deposition system. Magnetron sputtered commercial TiN/TiAlN coated tools were used for comparison in oxidation studies. They are known to be suitable for high speed machining on hardened steel. The layer structures of all the coatings are shown in Fig. 1.

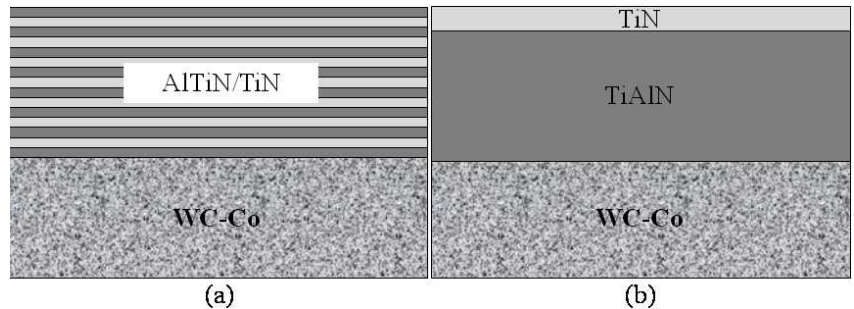

Fig. 1. Layer structure of the coatings: (a) nl-AlTiN/ TiN, (b) commercial TiN/TiAlN coating. 
Thickness measurements of all the coatings were carried out using a ball-cratering technique (Calotest), and it was measured as $\approx 3.2 \mu \mathrm{m}$ for the nl-AlTiN/TiN and $\approx 2.0 \mu \mathrm{m}$ for the commercial $\mathrm{TiN} / \mathrm{TiAlN}$ coating. The modulation period of the nl-AlTiN/TiN coating varies due to 3 -fold rotation of the substrate during deposition of the coating as reported by [8]. In the commercial inserts coated with TiN/TiAlN the top TiN layer is added only for coloring and easier identification of wear.

The microhardness of the coatings on D2 substrates was measured with Fisherscope H100C nanoindenter using Vickers indenter at room temperature. The calculation of hardness was performed according to Oliver and Pharr analysis [9]. Microhardness measurements were made at maximum load of $50 \mathrm{mN}$. The hardness of the nl-AlTiN/TiN coating was measured as $2996 \pm 150 \mathrm{HV}[5]$.

Oxidation tests of coated carbide tools were carried out in an air furnace at $1000^{\circ} \mathrm{C}$ for 1 and $2 \mathrm{~h}$. In the oxidation tests, the coated tools were put into the furnace, the temperature was increased from room temperature to $1000{ }^{\circ} \mathrm{C}$, and the samples were kept at the testing temperature for 1 or $2 \mathrm{~h}$, taking into account the application conditions of the cutting tools. After annealing durations, the heater was switched off and the tools cooled down to room temperature inside the furnace. After the tests, structure and chemical compounds of the coating were analyzed by scanning electron microscopy (SEM) and X-ray diffraction (XRD).

\section{Results and discussion}

Energy-dispersive X-ray spectroscopy (EDS) analysis shows that the nl-AlTiN/TiN contains $24.82 \% \mathrm{Al}$, $20.85 \% \mathrm{Ti}$ and $54.34 \% \mathrm{~N}$ in atomic scale. Chemical composition of the commercial TiN/TiAlN is $27.21 \% \mathrm{Al}$, $18.73 \% \mathrm{Ti}$ and $54.06 \% \mathrm{~N}$. SEM fracture cross-sections of the coatings are given in Fig. 2. The nl-AlTiN/TiN coating has a fine-grained dense structure, while the commercial TiN/TiAlN presents columnar structure. It is seen that the surface topography of the nl-AlTiN/TiN coatings is smoother than that of commercial TiN/TiAlN coating.
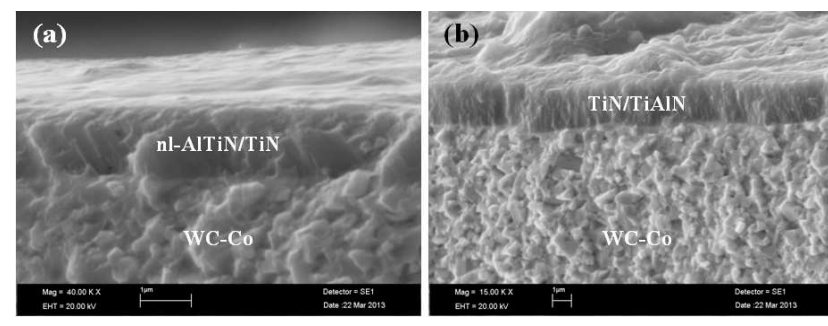

Fig. 2. SEM fracture cross-sectional images of as-deposited coatings.

X-ray diffraction patterns of the coatings after annealing at $1000^{\circ} \mathrm{C}$ for 1 and $2 \mathrm{~h}$ are shown in Fig. 3. In XRD pattern of as-deposited nl-AlTiN/TiN coating, only
c-TiAlN and WC phases were found. After annealing process, both coatings gave similar peaks and phases, and there is no change in the phases with increasing oxidation time. A decrease in the intensity of the peaks of the nl-AlTiN/TiN coating is seen after oxidation for $2 \mathrm{~h}$. The diffraction peaks of cemented carbide are also observed due to the small thickness of the coatings.

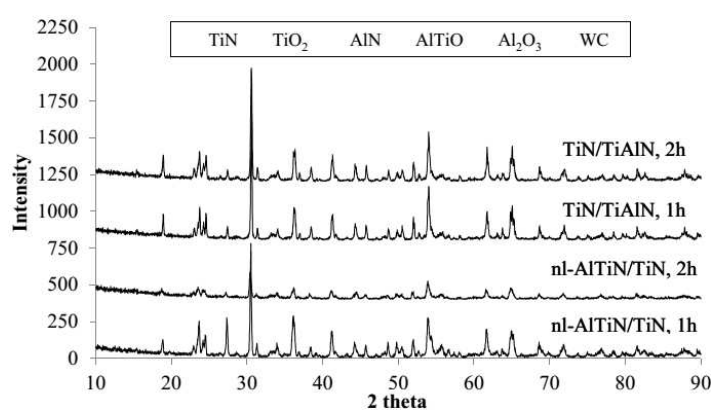

Fig. 3. XRD patterns of the coatings after annealing at $1000^{\circ} \mathrm{C}$ for 1 and $2 \mathrm{~h}$.

SEM fracture cross-sectional images of the coatings after oxidation at $1000^{\circ} \mathrm{C}$ for $1 \mathrm{~h}$ are shown in Fig. 4. As seen from the images, structure of the commercial TiN/ TiAlN coated tool changed more than that of the nl-AlTiN/TiN coated tool which is attributable to nanolayered structure of the AlTiN/TiN which retards the outward diffusion of $\mathrm{Al}$ and $\mathrm{Ti}$ and inward diffusion of $\mathrm{O}$ at $1000^{\circ} \mathrm{C}[6]$. It is observed that WC-Co tool also oxidized. According to EDS analysis, Co in the oxidized carbide layer disappeared after oxidation for $2 \mathrm{~h}$. The thickness of the oxidized carbide layer in the nl-AlTiN/ TiN coated tool is lower than that of commercial TiN/ TiAlN coated one. This shows that the nl-AlTiN/TiN acts as thermal barrier and decreases the further oxidation.
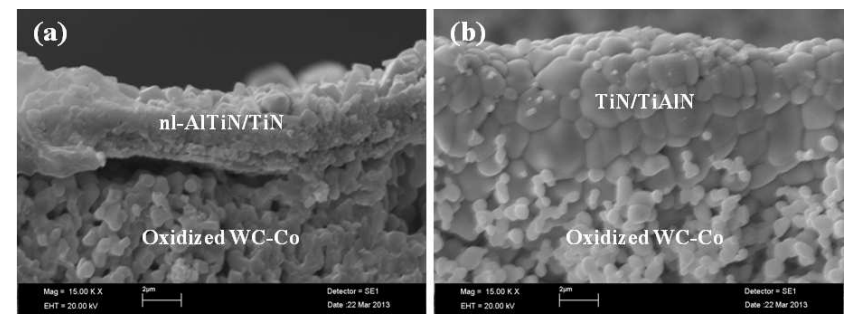

Fig. 4. SEM fracture cross-sectional images of the coatings after oxidation at $1000^{\circ} \mathrm{C}$ for $1 \mathrm{~h}$.

The cutting performance of the nl-AlTiN/TiN coating was investigated by Çalışkan et al. in face milling of AISI O2 cold work tool steel with hardness of $\approx 58$ HRc [5]. The cutting parameters used were the cutting speed of $150 \mathrm{~m} / \mathrm{min}$, the feed rate of $0.2 \mathrm{~mm} /$ tooth and the depth of cut of $0.5 \mathrm{~mm}$. The lifetime of the nl-AlTiN/TiN coated and commercial TiN/TiAlN coated cemented carbide cutting tools is compared in Fig. 5. The nl-AlTiN/ 
TiN coated tool exhibited $77 \%$ higher lifetime than commercial TiN/TiAlN coated tool due to its higher oxidation resistance, adhesion, toughness, and wear resistance. Similar findings were obtained by Chen et al. [6]. They achieved higher lifetime with cutting tools coated with TiAlN/TiN nano-multilayer coated tool both in turning of stainless steel and milling of $42 \mathrm{CrMo}$ steel when compared to single layer TiAlN coated tools.

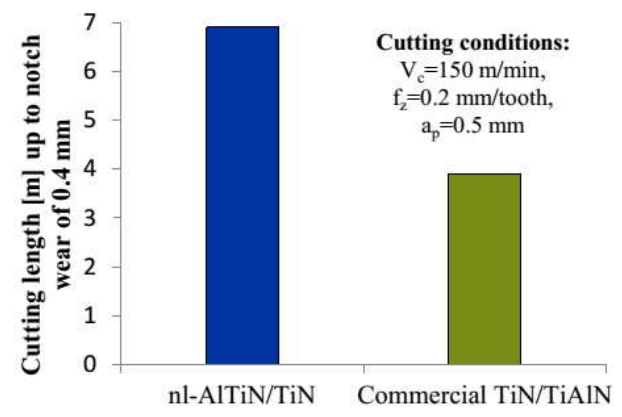

Fig. 5. Lifetime of the coatings in milling of AISI O2 hardened steel [5].

\section{Conclusions}

In this study, nanolayer AlTiN/TiN coating was deposited on carbide cutting tools, and the effect of nanolayered structure on the oxidation resistance of AlTiN and TiN coating was investigated at $1000^{\circ} \mathrm{C}$. Commercial TiN/TiAlN coated tools were used to make comparison in oxidation tests. It was found that after annealing process, both coating gave similar peaks and phases, and there is no change in the phases with increasing oxidation time. The structure of the commercial TiN/TiAlN coated tool changed more than that of the nl-AlTiN/TiN coated tool which is attributable to nanolayered structure of the $\mathrm{AlTiN} / \mathrm{TiN}$ which retards the outward diffusion of $\mathrm{Al}$ and $\mathrm{Ti}$ and inward diffusion of $\mathrm{O}$ at the test temperature. It is observed that $\mathrm{WC}-\mathrm{Co}$ tool also was oxidized. The thickness of the oxidized carbide layer in the nl-AlTiN/TiN coated tool is lower than that of commercial TiN/TiAlN coated one. This shows that the nl-AlTiN/TiN acts as thermal barrier and decreases the further oxidation.

\section{Acknowledgments}

The authors would like to thank Dr. Peter Panjan from Jožef Stefan Institute for his support in deposition of the nanolayered AlTiN/TiN coatings on carbide tools.

\section{References}

[1] Y.C. Chim, X.Z. Ding, X.T. Zeng, S. Zhang, Thin Solid Films 517, 4845 (2009).

[2] Z. Zhou, W.M. Rainforth, C. Rodenburg, N.C. Hyatt, D.B. Lewis, P.E. Hovsepian, Metallurg. Mater. Trans. A 38, 2464 (2007).

[3] P. Panjan, B. Navinšek, M. Čekada, A. Zalar, Vacuum 53, 127 (1999).

[4] F. Vaz, L. Rebouta, M. Andritschky, M.F. da Silva, J.C. Soares, J. Europ. Ceram. Soc. 17, 1971 (1997).

[5] H. Çalışkan, C. Kurbanoğlu, P. Panjan, M. Čekada, D. Kramar, Tribol. Int. 62, 215 (2013).

[6] L. Chen, Y. Du, X. Xiong, K.K. Chang, M.J. Wu, Int. J. Refract. Metals Hard Mater. 29, 681 (2011).

[7] H. Çalışkan, C. Kurbanoglu, D. Kramar, P. Panjan, J. Kopač, Eng. Sci. Technol. An International Journal (JESTECH) 15, 21 (2012).

[8] M. Panjan, M. Čekada, P. Panjan, A. Zalar, T. Peterman, Vacuum 82, 158 (2007).

[9] W.C. Oliver, G.M. Pharr, J. Mater. Res. 7, 1564 (1992). 